\title{
INTELECTUAIS DO PARTIDO DOS TRABA- LHADORES: PRINCÍPIOS E TENSÕES NA POLÍTICA EDUCACIONAL
}

\section{THE INTELLECTUALS OF THE LABOR PARTY: PRINCIPLES AND TENSIONS IN EDUCATIONAL POLICIES}

\author{
Rosely BITTENCOURT*
}

Resumo: Este estudo propõe um olhar específico sobre os intelectuais do Partido dos Trabalhadores, Cristovam Buarque, Tarso Genro e Fernando Haddad, objetivando compreender suas tensões e posições, tanto na academia quanto na gestão pública. Compreender as tensões, dilemas e conflitos que vivenciam os intelectuais do PT na relação entre as suas visões principistas e a realidade da política pública, orientada e conduzida pelo Partido, que possui suas próprias contradições, não permite explicações rápidas ou a universalização de respostas. Circular no universo dos intelectuais supõe estar aberto à multiplicidade de dilemas, distinção de tensões e particularização da continuidade e descontinuidade dos discursos.

Palavras-chave: Intelectuais. PT. Princípios. Tensões. Política pública. Educação.

\begin{abstract}
This investigation considers the intellectuals of the Labor Party, Cristovam Buarque, Tarso Genro and Fernando Haddad, and seeks to understand their positions and tensions, in both the academic environment as in public administration. Understanding the tensions, dilemmas and conflicts they experience the intellectuals of the Labor Party, in the relationship between their vision and the reality of public policy oriented and driven
\end{abstract}

*Doutora em Educação pela UDE. E-mail: roselybittencourt@hotmail.com 
Intelectuais do partido dos trabalhadores: princípios e tensões na política educacional

by the same party, with its own contradictions, does not allow quick explanations or universal answers. To participate of the world of intellectuals means to be open to the multitude of dilemmas, tensions and of continuity and discontinuity of discourses.

Keywords: Intellectuals. Labor Party. Principles. Tensions. Public policy. Education.

\section{INTRODUÇÃO}

Os intelectuais têm sido objeto de estudo desde muito tempo, apresentando-se sob a ótica da história dos intelectuais e da história das ideias, campos que, por vezes, confundem-se, mas que jamais se dissociam. Apesar da milenar importância na vida política do "intelectual que trabalha nas sombras do poder" (GALLARDO, 2008), o debate sobre os expertos ou técnicos é menos animado, o que não lhe tira o mérito ou importância. A vinculação entre a atividade intelectual e o poder, entre o saber e a intervenção na esfera política, entre expertos e políticas públicas é recorrente e invoca o debate em distintas áreas do conhecimento. A complexidade do tema perpassa pela influência do intelectual na vida pública, pela relação entre conhecimento e poder político, pela relação com o governo e a política partidária, ou, ainda, pela governabilidade.

Nossa proposta, embora circunscrita nesse enredo, não reclama participar desse complexo debate, menos ainda, induzir certezas ou posicionamentos definitivos, tampouco tem o propósito de universalizar respostas. Mais do que elencar elementos novos em um assunto tão transitado, motiva-se pela inquietação de compreender as tensões vivenciadas pelos intelectuais do Partido dos Trabalhadores - PT e suas posições, tanto na academia quanto na gestão política. Privilegia-se, neste estudo, o recorte da política pública da educação da primeira gestão (ocorrida entre 2003 e 2006) do primeiro partido de esquerda, de viés socialista, a assumir a Presidência da República no Brasil. O foco de atenção são os intelectuais do PT Cristovam Buarque, Tarso Genro e Fernando Haddad, seus dilemas e posicionamentos frente à gestão no Ministério da Educação - MEC, agência orientadora da política de educação brasileira. 
Estabeleceram-se algumas categorias teóricas no intuito de, a partir de diferentes perspectivas, construir um núcleo de apoio à pesquisa que aporte à relação entre as posições principistas dos intelectuais do PT e a conformação da política pública da educação. A primeira das categorias circunscreve-se na figura do intelectual como categoria social e, para tal, não foi possível declinar dos estudos de Gramsci e de seus conceitos de intelectual tradicional e intelectual orgânico. O sistema de relações, representação e reprodução no qual se insere o intelectual configurou-se em nova categoria. Assim, buscou-se a noção de espaço social em Bourdieu (1992, 1996), que descreve os contextos internos e externos do mundo social apontando para distintos campos de produção de conhecimento e suas instâncias de validação e reprodução, as quais permitem ampliar o marco de análise e as possibilidades compreensivas em relação à temática abordada. Para que se pudesse clarificar a função tecnocrática do intelectual ligado ao aparelho político-burocrático do Estado, bem como a relação entre saber intelectual e saber político, fez-se um novo recorte teórico recorrendo a Weber $(1980,2001,2002)$, cuja análise sobre a estrutura burocrática como aparelho de dominação e seus elementos de orientação normativa constituiu importante subsídio para nossa proposta.

Algumas inquietações guiaram esta investigação: quais as tensões e/ou contradições que tais intelectuais vivenciam? Qual a continuidade e descontinuidade na argumentação e discurso dos intelectuais em face da realidade da política educacional? O estudo realizado norteou-se, ainda, pelas seguintes hipóteses: o aparelho do Estado envolve intelectuais que sofrem com as contradições entre sua liberdade de pensamento e as demandas das políticas públicas; a gestão política tende a transformar o papel dos intelectuais em funções tecnoburocratas; os intelectuais vivenciam a tensão entre seus princípios e a orientação da política pública do partido com que simpatizam ou em que militam.

Por meio de livros e outras publicações, fez-se uso da pesquisa bibliográfica, situada numa perspectiva crítica como alternativa de análise da práxis e sendo utilizada como estratégia de reflexão da realidade, a fim de compreendê-la. A base empírica é fundada na pesquisa documental, fonte primária que utilizou documentos de domínio público como prática discursiva realizada por meio de argumentações de defesa de projetos, declarações, discursos oficiais, entrevistas e 
Intelectuais do partido dos trabalhadores: princípios e tensões na política educacional

leis, entre outros recortes privilegiados de opinião autorizada, para analisar as informações brutas e extrair delas o sentido das distintas posições. O tratamento dos dados, de caráter qualitativo, tem como matéria-prima o discurso, consolidado em um sistema de ações entre múltiplas forças, afetado e constituído por relações de poder.

As inquietações que guiaram esta investigação se postam, portanto, no cruzamento entre intelectuais e política, procurando articular duas linhas de análise: a primeira preocupa-se em explorar os posicionamentos e conteúdos que caracterizam os marcos ou perspectivas teóricas dos intelectuais do Partido dos Trabalhadores; a segunda atém-se à ação política de tais intelectuais, particularizando a ação junto ao Ministério da Educação.

Porém, compreender as tensões vivenciadas pelos intelectuais em tela supõe verificar, atentamente, não somente as semelhanças, diferenças e contradições existentes entre a realidade da política pública e a produção discursiva desses intelectuais, mas, igualmente, a lógica do Partido, suas próprias tensões, continuidades e descontinuidades. Diante disso, optou-se por introduzir a temática a partir do Partido dos Trabalhadores, não como intelectual coletivo, mas como pano de fundo ou cenário no qual transitam os intelectuais em destaque.

\section{PARTIDO DOS TRABALHADORES - DA AÇÃO SINDICAL A PARTIDO DE GOVERNO}

No ano de 2002, ascende ao poder no Brasil o Partido dos Trabalhadores, um partido de massas, plural e de viés socialista que assume a tarefa histórica de construção de um projeto alternativo de nação. O PT foi o primeiro partido de esquerda, de viés socialista, a assumir a Presidência da República do Brasil, um país com características de modernização conservadora. No lapso entre a fundação da organização partidária e sua ascensão ao Governo, o PT vive dilemas e conflitos, continuidades e descontinuidades, fraturas e reconstruções.

O Partido dos Trabalhadores emerge com os movimentos sociais e sindicais em fins da década de 1970, a partir da necessidade de construir um canal de expressão política e partidária dos trabalhadores, de resistência à exploração capitalista, de contestação e oposição ao regime militar. Nasce da conjunção de um novo sindicalismo, pragmático e voltado às necessidades imediatas do trabalhador, com as 
experiências da esquerda remanescente e a contribuição conceitual e teórica da intelectualidade. Caracteriza-se, portanto, como um Partido de massas que acolheu a diversidade de tendências sem advogar uma filosofia única, mas com unidade de horizonte: construir o socialismo e uma sociedade sem opressores e oprimidos.

O PT formaliza-se no ano de 1980 como um partido plural e compromissado com a causa dos trabalhadores, o socialismo e a democracia plena. (PT, 1980). Seu norteador nesse período é um novo projeto societário a partir da "ditadura do proletariado" e da participação popular, fortemente influenciado pela ética bolchevique de ditadura do proletariado. A tomada do poder do Estado pelos trabalhadores é condição fundante a uma nova sociedade, acrescendo a defesa de formas diretas e massivas de participação popular para a realização desse projeto societário. Engajado nas lutas sociais e intimamente ligado aos movimentos populares, nos moldes dos partidos revolucionários do século XX, o PT da década de 1980 representa a visão messiânica e o discurso transformador. (GENOINO, 2005).

Sua opção pelos oprimidos o faz rejeitar os opressores, advogando a superação do capitalismo, questionando a macroestrutura de poder, o imperialismo, o latifúndio e o monopólio, bem como recusando a classe dos patrões. Seu discurso é o da ruptura com a ordem econômica capitalista, dependência externa, acordos com o FMI, controle dos monopólios e com os latifúndios. Para conseguir a ruptura necessária, defende a emancipação e a independência político-ideológica dos setores populares, por meio da participação organizada e consciente. Propõe um governo democrático popular revolucionário, compromissado com a liberdade e a igualdade, que prepara as condições políticas e acumula forças para a revolução socialista. (PT, 1979).

Na década de 1990, o PT abandona o discurso de ruptura e de ditadura do proletariado, e privilegia o eixo de argumentação na exclusão e na pobreza, subordinando a ele as questões macroestruturais. Define o "Socialismo Petista" (PT, 2008) a partir da vocação democrática e do compromisso libertário em favor de uma sociedade com justiça social e sem opressão. Recusa qualquer pretensão imperial e rejeita todas as formas de opressão e exploração entre os povos do

\footnotetext{
${ }^{1}$ Documento referendado no $2^{\circ}$ Congresso, realizado entre 24 e 28 de novembro de 1999 , em Belo Horizonte, onde o PT reafirma a opção anticapitalista de caráter socialista.
} 
mundo. Não concebe socialismo sem democracia, sendo esta a condição fundamental para assegurar que as maiorias sociais governem e efetivem o projeto de nação.

O socialismo petista é um projeto-síntese da unidade na pluralidade de culturas, pensamentos e ideais. No PT convivem dialeticamente diferentes correntes de pensamento democrático e transformador: cristianismo social, marxismos, socialismos não-marxistas, democratismos radicais, doutrinas laicas de revolução comportamental, entre outras, cujo ponto de convergência é o projeto de uma sociedade sem exploração e opressão.

Para a definição do socialismo petista, buscou-se "evitar tanto o ideologismo abstrato, travo elitista da esquerda tradicional brasileira, quanto o pragmatismo desfibrado, característico de tantos outros partidos". (Id. Ibid.). O socialismo petista é caracterizado como um projeto humano coletivo, que não nega a singularidade; é radicalmente democrático e emancipador, fundado no princípio da solidariedade e da ética, que amplia as liberdades democráticas duramente conquistadas na sociedade capitalista e conjuga a participação das massas nos vários níveis de direção do processo político e da gestão econômica, com os instrumentos da democracia representativa e direta.

$\mathrm{Na}$ ótica dos interesses democráticos e populares, o PT institui o Governo Paralelo, instrumento de avaliação crítica do governo Collor e mobilizador de propostas alternativas à ofensiva neoliberal, e se propõe a conhecer a realidade brasileira, seus problemas, anseios e soluções para um futuro diferente. Percorrer o Brasil, de um extremo ao outro, com o objetivo de realizar uma "radiografia" do país e mostrar o Brasil esquecido ao Brasil oficial e ao restante do mundo foi a tarefa das "Caravanas da Cidadania", responsáveis por (re) direcionar o eixo da argumentação do Partido para a exclusão e a pobreza.

O PT da década de 1990 propõe a subordinação do econômico ao social e estabelece defesa em favor de uma modernidade dos fins ou modernidade ética, baseada na inversão das prioridades que até então nortearam os governos do Brasil. Busca submeter seus objetivos à meta central de combate à pobreza e à indigência, que atingem metade da população brasileira. (PT, 1994).

Tendo como princípio a participação popular para a reorganização das prioridades e a garantia de exercício da cidadania, o PT argumenta que a conquista da cidadania integral não se limita à incorporação pelo Estado das demandas de diferentes setores exclu- 
ídos da sociedade, mas exige tratamento desigual dos desiguais, por meio de políticas afirmativas que mantenham as identidades individuais e construam uma identidade comum às maiorias nacionais. Desse modo, os interesses de classe dos trabalhadores, os direitos das mulheres, negros, povos indígenas, portadores de deficiência, crianças, jovens, adolescentes e terceira idade compõem, a partir da incorporação desses segmentos no processo político democrático, a proposta de universalização da cidadania no Brasil.

Afirmando-se como um partido pós-comunista, que não busca tomar o poder pela revolução armada, e pós-social-democrata, que não visa conquistar o governo para amenizar o capitalismo, o PT vislumbra, na Revolução Democrática, a possibilidade histórica do socialismo democrático no Brasil livre, igual e solidário. A proposta de revolução democrática de combate à exclusão, à segregação, à discriminação e ao preconceito, que busca preservar a vida e democratizar o Estado, a propriedade e a riqueza, tem como eixo central a educação, prioridade máxima.

Nos anos 1990 o PT é considerado o principal partido de esquerda do Brasil e a alternativa para um novo projeto de sociedade. Abre-se a uma ampla frente de alianças e de apoio com os partidos de esquerda, na intenção de realizar a revolução democrática com propostas de largo prazo, para combater a exclusão, romper com a ordem neoliberal e refundar a perspectiva socialista para o país.

É com a imagem consolidada de um partido assentado na ética e no combate à corrupção que o PT ascende ao poder em 2002, agora com o apoio centrista e aliado a antigos adversários políticos e empresariais. O perfil de apoio aceito pelo PT difere daquele que se aceitou nas eleições anteriores, sob o argumento de que os interesses do país são maiores que as diferenças ideológicas. Nas palavras do Presidente Lula, isso significa que o governo "terá a marca do entendimento e da negociação. Da firmeza e da paciência. Temos plena consciência que a grandeza dessa tarefa supera os limites de um partido". (LULA DA SILVA, 2008).

A serenidade, a tranquilidade e a cautela cimentam a moderação do discurso do recém-eleito Presidente Lula e minimizam os temores do mercado financeiro e da população acerca das mudanças a serem realizadas no país: "A sociedade está convencida de que o Brasil continua vulnerável e de que a verdadeira estabilidade precisa ser construída por meio de corajosas e cuidadosas mudanças". (LULA 
DA SILVA, 2008a). O Presidente salienta, em seu discurso, a ideia de que o crescimento econômico deve ocorrer com responsabilidade social, de modo a manter a estabilidade. Buscando preservar a confiança no novo Governo e cumprir seus compromissos, ressalta: “[...] premissa dessa transição será naturalmente o respeito aos contratos e obrigações do País". (Id. Ibid.). A proposta de transição para o novo Governo é "lúcida e criteriosa" e as mudanças são democráticas.

O Governo, então caracterizado como de "centro-esquerda", imprime uma visão humanista às suas propostas, tendo o social como o eixo do desenvolvimento de um novo projeto de nação, democrática e configurada por um novo contrato social. Considera que democracia política deve caminhar junto com democracia econômica e social, tendo como prioridade os direitos humanos e a cidadania, a reforma das instituições e o controle democrático do Estado pela sociedade.

Por essa razão, privilegia as políticas sociais, em especial a assistência social e a educação, criando mecanismos de ações afirmativas e de redistribuição de riqueza. A educação, entendida como base de cidadania e instrumento para o desenvolvimento e inserção competitiva da nação, é tida como prioridade, da "creche à pósgraduação".

Já no início da gestão do PT na Presidência da República, a polarização entre "radicais" e "moderados" dentro do Partido ganhou novos contornos quando o Governo apresentou à Câmara e ao Senado as Reformas da Previdência e Tributária. Declaradamente contrários às propostas do Governo, os integrantes da ala radical se posicionam e são expulsos do Partido.

A partir do ano de 2005, o PT vivencia um processo de crise interna desencadeada por denúncias ${ }^{2}$ de corrupção junto ao Congresso Nacional e fortemente exploradas pela mídia, causando fraturas importantes na estrutura institucional. A crise foi deflagrada pelo "Escândalo do Mensalão", suposto esquema de compra de votos de parlamentares em favor de projetos do Governo, que resultou na aceitação, pelo Supremo Tribunal Federal, de denúncias contra quarenta acusados de envolvimento no "esquema". Dentre esses acusados estão nomes importantes da diretiva do Partido e do Governo, como

${ }^{2}$ Entre os anos de 2005 e 2006 variadas denúncias envolveram o Partido dos Trabalhadores, porém não ficaram restritas somente a esse partido. Os escândalos que desencadearam essas denúncias foram amplamente divulgados pela imprensa escrita e falada e podem ser facilmente acessados pela internet. 
os ministros José Dirceu - Casa Civil, Luiz Gushiken - Comunicação e Gestão Estratégica, e Anderson Adauto - Transportes; Silvio Pereira, Secretário Geral do PT; Delúbio Soares, Tesoureiro do PT; os deputados João Paulo Cunha e José Genoino, ambos do PT-SP; e, ainda, integrantes de outras legendas. Nesse período, eclodiram outros tantos escândalos envolvendo integrantes da cúpula do Partido ou parlamentares.

Assim, não conseguindo evitar o desgaste natural das disputas político-partidárias e, ainda, confrontando-se com suas próprias contradições ao ver desmoronado um dos seus pilares de sustentação - a ética, o PT é consumido pela crise. Soma-se a isso a crítica de integrantes do Partido ao apoio centrista e aos compromissos firmados para a conquista do Governo; as expectativas não atingidas e a defesa de propostas antes contestadas. E há, ainda, o embate do PT com o Governo que o representa. A crise interna do Partido e deste com o Governo provoca fraturas que o impelem a buscar renovação e fortalecimento.

As tensões e mudanças vivenciadas pelo PT propiciam uma linha de entendimento dos dilemas de seus intelectuais Cristovam Buarque, Tarso Genro e Fernando Haddad, que, oriundos da academia e militantes do Partido, assumem função na estrutura burocrática do Estado, respondendo pela elaboração e efetivação da política pública da educação. Os três intelectuais possuem antiga relação com o Partido e, com maior ou menor proximidade, acompanharam sua trajetória e com ele partilharam certezas e incertezas, o que permite inferir que, se o PT vivenciou continuidades e descontinuidades, isto também ocorre com os seus intelectuais.

\section{A LEALDADE DE PRINCÍPIOS EM CRISTOVAM BUARQUE}

É circunscrevendo os intelectuais no cenário a que nos referimos que aportamos em Cristovam Buarque, um intelectual que, quando jovem, militou em movimentos e partidos de esquerda, foi exilado pelo regime militar, ingressou em organismos internacionais de desenvolvimento e de educação, filiou-se no PT em 1989, assumindo atividades de representação partidária e participando, por uma gestão, do Diretório Nacional do Partido.

Atente-se que a relação de Cristovam Buarque com o Partido inicia quando este deflagra o rompimento com o discurso revolucioná- 
rio de estilo bolchevique e assume a opção pelos pobres e excluídos. Buarque integrou as Caravanas da Cidadania e o Governo Paralelo e tem suas ideias estampadas nos Planos de Governo para as eleições presidenciais, com uma defesa humanista explícita de Modernidade Ética, inversão de prioridades e educação como base de cidadania, o que denota o reconhecimento do Partido.

De acordo com os dados levantados na pesquisa, Cristovam Buarque possui estreita afinidade com a educação. Apesar de sua formação técnica - engenheiro mecânico com doutorado em economia - tem na educação uma utopia e nela "milita" desde os quatorze anos de idade, quando inicia sua carreira docente. No campo pedagógico, atua em universidade pública (desde 1979) e assume posições de destaque no âmbito institucional (1985 a 1988). No campo da produção discursiva, cujas ideias circulam por diferentes áreas de conhecimento, dá ênfase à educação e agrega expressivo capital simbólico, o que lhe permite autonomia na construção intelectual.

Os conceitos de Modernidade Técnica e Modernidade Ética, modelos de desenvolvimento norteados, respectivamente, pelo progresso material e pela subordinação da racionalidade econômica ao social, são criados por Cristovam Buarque. Para ele, a Modernidade Técnica representa o padrão de sociedade atual, desumanizante, injusto e apartado, enquanto a Modernidade Ética evidencia um projeto alternativo de sociedade, alicerçado na igualdade, liberdade, paz e justiça social. O referido intelectual defende um modelo ético e social de modernização brasileira, construído a partir do desejo utópico de rompimento com o modelo de modernidade vigente. Ele possui compromisso político com um socialismo de novo tipo, que pode ser chamado de socialismo humanista, sociedade utópica ou modernidade ética, visto que não se prende à terminologia, mas à proposta de um processo civilizatório ético, estético e social.

Coerente com os valores humanistas, Cristovam Buarque subordina os princípios do partido aos seus princípios utópicos de uma nova sociedade. E, de forma surpreendente, mantém coerência entre suas formulações teóricas e a ação política realizada desde a academia até a representação partidária. Caracteriza-se, portanto, como um intelectual "à francesa", que a exemplo de Sartre em relação ao Partido Comunista, "é companheiro de rota" do Partido dos Trabalhadores, sendo este somente um instrumento para conquistar seus objetivos. 
Avessa à tecnocracia, sua visão humanista de Modernidade Ética, possivelmente influenciada pelo período em que estudou na França, permite entender a centralidade da educação em seus discursos e ações. Obsessivamente, advoga em favor da educação como instrumento para uma nova matriz social, sem apartação, com justiça e equidade. Seu olhar é dirigido particularmente à educação básica; contudo, defende mudanças na universidade (assim como nos intelectuais e partidos de esquerda), para a construção de novos conceitos e novas utopias. Para recuperar a função social da universidade, propõe a implantação de "Universidade Tridimensional" e a traduz em ação quando, como reitor da UnB - Universidade de Brasília (1985-1988), cria tal estrutura, com departamentos, núcleos temáticos e culturais que colocam a técnica a serviço de um projeto ético e resgatam seu papel epistemológico, poético e social.

A mesma coerência principista se apresenta no Governo do Distrito Federal, quando Buarque desenvolve programas e ações, em consonância com a proposta de revolução nas prioridades, e cria o programa ícone de sua vida pública - Bolsa Escola -, disseminando-o ao Brasil e ao mundo por meio da ONG Missão Criança. A opção pela educação básica como motor propulsor de um projeto de nação norteia sua ação no Ministério da Educação, onde atua também no sentido de imprimir um novo olhar à educação superior, mesmo tida como secundária. Dirige cobranças ácidas ao Partido e ao Governo, no intuito de conseguir adesão ao projeto ético de nação e à prioridade da educação.

Permanece no Ministério da Educação pelo período de um ano, mas é demitido pelo Presidente da República, que justifica a decisão pela ausência de resultados e pelo excesso de discursos e teorias. Cristovam Buarque, cujo sonho confesso era ser ministro da educação, frustra-se ao não concluir o trabalho iniciado e ao perceber que o PT não partilhava a utopia de uma modernidade ética, não se mantendo leal à proposta de centralidade na educação, tida como prioridade.

No Senado, seus discursos se mantêm ácidos e qualificam a subordinação dos princípios do PT aos seus próprios princípios. Suas ações evidenciam que atribui menor importância à ideologia partidária e maior ao compartilhamento do compromisso com a educação. Agindo com o mesmo nexo, desvincula-se do PT e filia-se ao PDT - Partido Democrático Trabalhista, cuja história é ligada a dois grandes defensores da educação, Leonel Brizola e Darcy Ribeiro, e cujo estatuto, 
Intelectuais do partido dos trabalhadores: princípios e tensões na política educacional

de forma inédita, assegura compromisso com a educação e a coloca como prioridade.

Como se observa, Cristovam Buarque é um intelectual pouco ortodoxo, autônomo e não orgânico ao Partido dos Trabalhadores. Tem uma ação política coerentemente articulada com sua formulação de socialismo humanista, denotando lealdade aos seus próprios princípios e não temendo críticas ou incompreensões. A visão humanista e seus valores alicerçam suas posições, a ponto de ser conhecido como um "semeador de utopias".

\section{A ORGANICIDADE DE TARSO GENRO}

Em evidente intenção de viabilizar resultados diferentes dos que, até então, haviam sido conseguidos por Cristovam Buarque na implantação do Programa de Governo para a Educação, na reforma ministerial de 2004 o Governo Lula define Tarso Genro para o Ministério da Educação. A decisão presidencial também alude ao pouco vínculo de Tarso Genro à academia e ao fato de não se pautar em "teoricismos". Quanto à academia, os dados coletados demonstram que Tarso Genro possui pouco vínculo com o campo pedagógico, porém agrega expressivo capital simbólico no campo da produção discursiva, representado tanto pela quantidade e variedade de publicações no Brasil e exterior, quanto pelo título de Doutor Honoris Causa, recebido no ano de 2006, que o distingue pelo saber na área da teoria política.

No campo político, a inserção de Tarso Genro ocorre na década de 1960, quando ainda cursava a graduação em Direito, medrando fortes laços. Nesse período, militou e desenvolveu atividades de representação política em partidos de esquerda que defendiam um projeto contra-hegemônico. Quando estava na ala vermelha do PC do B - Partido Comunista do Brasil, é preso pelo regime militar e refugia-se no Uruguai; ao retornar, no ano de 1980, funda um partido de orientação comunista, mas logo migra para o Partido dos Trabalhadores, assumindo funções de representação partidária em quatro pleitos eleitorais no estado do Rio Grande do Sul (1986, 1988, 1992, 2000). Integrante da ala moderada, vincula-se ao campo majoritário e compõe o Diretório Nacional por sete gestões, o que significa que participou diretamente das decisões e mudanças ocorridas no interior do Partido. 
Tarso Genro é reconhecido como um dos principais ideólogos do PT, sendo suas ideias facilmente localizadas em documentos de orientação do Partido, como "O Socialismo Petista". Influenciado por sua formação e especialização acadêmicas, tem no Direito o pilar de análise para construir reflexões sobre o Estado, o trabalho e a sociedade. Caracterizado como um intelectual crítico, identificado organicamente com o Partido, advoga em favor da ideia de um projeto de nação socialista, radicalmente democrático, humanista, sustentado em um novo contrato social que permita o surgimento de novas formas de constituição das maiorias na sociedade, isto é, com a constituição de uma nova esfera pública não estatal, capaz de realizar o controle e indução do Estado, articulada com a representação delegada, de modo a imprimir-lhe legitimidade.

A combinação entre democracia direta e democracia representativa, que se traduz no conceito de nova esfera pública não estatal, funda-se na utopia da emancipação humana, pressupondo novas formas jurídicas de regulamentação ajustada aos valores da sociedade que demandam consumo e criam necessidades artificiais, orientandoos para um novo modo de vida, solidário e justo. Um "modo de vida conscientemente orientado" implica renúncia em favor da inclusão das massas. Para tanto, envolve a criação de alternativas que permitam às pessoas decidir, em condições de mínima igualdade, sobre questões de interesse público, de modo a limitar a desigualdade máxima ou pautar uma igualdade mínima.

A vocação radicalmente democrática e o compromisso libertário com a justiça expressam a defesa de um projeto de nação socialista, cimentado na subordinação da economia e do mercado às políticas sociais e no rompimento com a opressão e exclusão. Socialismo e democracia são tratados, tanto por Tarso Genro quanto pelo PT, como uma ideia reguladora para a equidade social, manutenção de equilíbrios, aproximação entre Estado e sociedade, e afirmação dos direitos humanos e sociais. No PT e em Tarso Genro, a democracia é determinante para um projeto de nação, sendo refletida internamente por meio do pluralismo de tendências e pensamentos, da posição dialógica de unidade na diversidade e da relação com as bases e com a sociedade.

A ação política de Tarso Genro ocorre entre o Partido dos Trabalhadores e a gestão pública desse mesmo partido, isto é, entre a representação e organização partidária e as funções tecnocráticas 
Intelectuais do partido dos trabalhadores: princípios e tensões na política educacional

desenvolvidas junto ao seu Governo. Na Prefeitura de Porto Alegre consolidou o "Orçamento Participativo" (OP), marca do PT nas administrações municipais. Em total consonância com as orientações do Partido, legitima no âmbito local o discurso teórico de democracia direta aliada à representação parlamentar, por meio de um novo espaço público de participação, não estatal, para o controle e indução sobre o Estado. A experiência do OP junto à Prefeitura de Porto Alegre funde em uma só esfera a heteronomia legitimada pela delegação parlamentar com a autonomia da sociedade civil, no controle, elaboração e execução do Orçamento da cidade, por onde passa o poder real do Estado e são mediados os interesses grupais de classe.

Atuando como secretário especial do Conselho de Desenvolvimento Econômico e Social - CDES, que reúne representantes do poder público e da sociedade, dentre os quais trabalhadores, empresários, líderes de movimentos sociais, Tarso Genro mantém coerência com as orientações do Partido e com a linha de um novo padrão democrático do Estado. O CDES, cujos integrantes são designados diretamente pelo Presidente da República, configura-se como um órgão de articulação e integração entre a sociedade civil organizada e o Estado, na via de um novo contrato social cuja estratégia é a escuta ativa e o diálogo para a construção compartilhada das ações do Governo, em um projeto de desenvolvimento de longo prazo.

Tarso Genro permanece no CDES pelo período aproximado de um ano, quando migra para o Ministério da Educação na primeira reforma ministerial do Governo Lula. Respondendo à confiança que lhe foi dedicada para traduzir em ações concretas os importantes compromissos assumidos pelo PT ao ascender ao poder, o então ministro organiza e inicia a implantação das propostas-âncora do Programa de Governo e viabiliza canais de participação, controle e decisão da sociedade sobre a educação.

Em meio à crise interna do Partido, deixa o MEC para ocupar, de forma interina, a Presidência do PT, a fim de minimizar os conflitos e promover a transição para o Processo de Eleições Diretas (PED). No PED desse mesmo ano (2005), Tarso Genro se lança candidato à Presidência do Partido; no entanto, retira sua candidatura quando o campo majoritário do partido se nega a excluir de sua chapa José Dirceu, cassado pela Câmara dos Deputados. Buscando restabelecer o equilíbrio interno do PT, participa da "desarticulação" do Campo Majoritário, do qual também "fez" parte, e da mobilização interna para 
reorganização ou "refundação" do Partido, a partir de suas fraturas. Avalia que a crise interna do PT e deste com o Governo denuncia a necessidade de construir no interior do Partido uma nova concepção de socialismo, não mais idílica ou messiânica, mas adequada à nova realidade mundial e ao momento histórico brasileiro, com propostas realistas e exequíveis. Dessa forma, reitera seu apoio ao Governo, o qual, a seu ver, realiza uma gestão possível, sem perder a utopia.

Sob o olhar da realidade política e da produção e geração de políticas públicas, pode-se inferir sobre a fusão entre o papel do intelectual e do partido, o que lhe assegura organicidade. Integrante da ala moderada e do corpo diretivo do PT, Tarso Genro tem sua linha de pensamento vinculada às dimensões estratégicas e programáticas, coerentemente articulada com os norteadores do Partido, o que não significa que se despe de sua função crítica. Suas posições e críticas ocorrem no sentido de apontar necessidades e possibilidades de correção sem provocar fraturas no interior do PT ou mesmo de seu Governo, o que significa dizer que, como integrante do Partido, não perdeu a crítica ao olhar para o próprio PT, investindo energia em dar-lhe um novo rumo, compatível com as transformações da realidade.

Superada a crise do Partido, Tarso Genro em 2006 retorna ao Governo, passando a ocupar a função de Ministro Chefe de Relações Institucionais da Presidência da República e, em 2007, a de Ministro da Justiça, o que evidencia o seu reconhecimento junto à legenda e seu Governo. Em seu lugar, no Ministério da Educação, assume Fernando Haddad, que, na ocasião, já compunha a equipe desse ministério.

\section{FERNANDO HADDAD: INTELECTUAL OU EXPERTO?}

A história pessoal e/ou familiar deste intelectual aponta para a compreensão tanto do vínculo que ele possui com o trabalho, como de suas opções acadêmicas. Fernando Haddad é filho de camponês libanês que imigrou para o Brasil e montou um comércio de tecidos situado na Rua 25 de Março, em São Paulo, tradicional reduto da comunidade de descendentes de libaneses paulistanos. Auxiliou o pai nesse comércio e se graduou em Direito (1985), opção justificada por fatos jurídicos ocorridos no âmbito familiar. Atuou como advogado e se destacou no campo pedagógico, vinculado à Universidade de São Paulo - USP, onde não só realizou sua formação, da graduação em Direito ao doutorado em Filosofia (1990), mas também se inseriu 
na prática pedagógica logo após graduar-se, ocupando posições de coordenação (1998) e se mantendo até hoje como professor doutor.

No campo acadêmico, assume uma função discursiva mediada por novas interpretações teóricas e históricas; todavia, suas formulações não lhe garantem grande capital simbólico, pois, apesar da qualidade e profundidade, suas publicações, com forte traço de origem na produção acadêmica, são escassas e de pouca circulação. A qualidade de sua produção intelectual garantiu-lhe cadeira em diversos conselhos editoriais de revistas à esquerda, ligados ou não ao Partido dos Trabalhadores.

A produção teórica de Fernando Haddad versa sobre o Estado e o mundo do trabalho, articulando a crítica às principais concepções construídas historicamente e à recuperação de valores libertários. A importância de sua construção teórica reside, particularmente, no repensar o legado marxista e em restabelecer a dialética para o entendimento da realidade atual. Sua base de análise é Marx, apoiada por Adorno, Habermas, Horkheimer, Dahendorf, Braverman, Djilas, Burnhan, Giddens, Gorz, Mallet, entre outros, para edificar seus raciocínios.

Fernando Haddad consolida o entendimento de que a dialética é uma metalinguagem que possibilita acesso aos nexos da vida social (a linguagem e o trabalho), ou é considerada como um nível dos processos de produção em que as relações sociais podem ser pensadas historicamente. Concebe que o trabalho, ao transformar a natureza para adequar o mundo às necessidades humanas, liberta os homens e permite a expansão do universo lingüístico. Aporta, ainda, na análise do valor trabalho, da reprodução da força de trabalho e da luta do trabalhador.

Inovando nas interpretações históricas do socialismo, em particular do sistema soviético, Haddad caracteriza-o como um modelo de acumulação primitiva de capital, não capitalista e anticapitalista, sustentado pela intervenção do Estado e pelo rompimento da propriedade privada dos meios de produção, estabelecendo possibilidades para o socialismo na sociedade superindustrial.

A sociedade superindustrial, cuja base técnica é a telemática, desenvolve-se com a incorporação da ciência como fator de produção, condição e resultado da reprodução capitalista. Para que isso aconteça, apoia-se num padrão tecnológico que submete a natureza e estabelece um perfil de demanda que, ao desequilibrar a relação entre as necessidades do homem e a satisfação de tais necessidades, alimenta a luta de classes. 
Segundo Haddad, as classes sociais na superindústria se apresentam reconfiguradas em quatro grandes classes sociais: a classe dos trabalhadores assalariados interiores à produção; a classe constituída pelos proprietários do capital, pelos funcionários do capital - alta gerência - e pelos proprietários fundiários; a classe dos agentes sociais inovadores, portadores do conhecimento científico-tecnológico aplicado à produção; e a classe - ou não classe - dos desqualificados, dos não trabalhadores. Observa-se, também, na superindústria, a existência de três camadas sociais que não pertencem a qualquer das classes sociais citadas: a dos domésticos, que vendem sua força de trabalho como valor de uso; a dos autônomos, que vendem bens e serviços produzidos com meios próprios; e a dos funcionários públicos.

Fernando Haddad defende a ideia de que a implantação de um novo projeto de sociedade supõe subverter o padrão tecnológico vigente - o qual mantém privilégios e cria necessidades ao invés de satisfazê-las -, direcionando a inovação tecnológica para um novo padrão de demanda, com distribuição de renda, socialização da propriedade privada, alargamento do espaço democrático e participação popular, o que significa ter como referência a opção ética pela vida. O cooperativismo é uma possibilidade de negação do capitalismo; portanto, o novo socialismo tem no trabalho cooperativo um retorno ao caminho da emancipação, e na psicanálise social uma possibilidade de leitura dos indivíduos em termos de consciência e inconsciência. Um projeto de país socialista deve se aproximar de todas as classes e camadas sociais, tanto das forças produtivas quanto das improdutivas, focando-se na emancipação, por meio de um esforço de mediação e protagonismo do Estado e da articulação das dimensões econômica, social e política com os sistemas estatais.

A produção intelectual de Fernando Haddad submete-se à importância e ao forte traço de sua experiência na gestão pública. Respeitado, particularmente, pela atuação na gestão pública, tem sua prática vinculada à ação de governo do PT, seja no nível municipal ou federal. Iniciou sua carreira pública como chefe de gabinete da Secretaria de Finanças de São Paulo (2001 a 2003), na gestão de Marta Suplicy. Por se tratar de uma secretaria-meio, cujo objetivo é definir as dotações orçamentárias do município, dirigiu especial atenção à educação, maior orçamento da prefeitura da cidade de São Paulo e, também, um dos maiores orçamentos públicos do país.

Para a área da educação, Haddad idealizou os Centros Educa- 
cionais Unificados - CEUS, uma das grandes marcas da administração municipal da época. Sensibilizado com a ausência do Estado nos grandes bolsões de pobreza da região, resgata a ideia de "escolas-parque", de Anísio Teixeira, propondo núcleos com urbanização e espaços físicos que agreguem educação, infraestrutura, cultura, esporte e lazer, evidenciando a presença do Estado. O Projeto Universidade para Todos - ProUni, que propõe a abertura de vagas em instituições privadas por meio de incentivos fiscais, surge na Prefeitura da São Paulo e é instituído em Lei, porém não operacionalizado, sendo também atribuído a Fernando Haddad.

Seguindo a linha de Gestão do PT nas administrações municipais, Haddad envolve-se na implantação de programas sociais de renda mínima, capacitação profissional, geração de renda e cooperativismo, que na época eram ligados à Secretaria de Finanças. Em iminente crise dessa administração pública, com avaliação negativa da opinião pública, críticas referentes ao aumento de impostos e à criação de um sistema de taxação, bem como supostas irregularidades nas contas municipais, ele desloca-se para o Governo Federal no segundo semestre de 2003.

No Ministério do Planejamento, na função de assessor especial, formula e inicia a implantação do projeto Parceria Público-Privada - PPP, que prevê a realização de obras de infraestrutura pela iniciativa privada a partir de aporte financeiro do setor público. As PPPs se transformaram na grande aposta do Governo Lula para melhorar a infraestrutura e minimizar o déficit de investimentos em serviços públicos, acelerando o crescimento e evitando o estrangulamento da economia. Com menos de um ano no Ministério do Planejamento, migra para o Ministério da Educação na função de Secretário Executivo (2004 a 2005) e, posteriormente, substitui Tarso Genro na posição de ministro.

No Ministério da Educação, onde permanece até a presente data, Haddad defende uma visão sistêmica da educação e implanta projetos que respondem aos compromissos do Plano de Governo. Tem a oportunidade de implantar o ProUni, proposta gestada ainda na Prefeitura de São Paulo, e propostas para todos os níveis educacionais, da "creche à pós-graduação", buscando articular as dimensões econômica, social e política na educação.

Fernando Haddad é filiado ao PT desde 1983, sem assumir papel na diretiva do partido, mas contribuindo para a sustentação técnica das propostas de Governo, mesmo antes de ascender ao po- 
der, por meio do Instituto Cidadania, ONG formada por intelectuais, técnicos e lideranças, encarregada de elaborar propostas para as políticas públicas do $\mathrm{PT}$ e, por conseguinte, um projeto alternativo de nação.

Analisando a trajetória desse intelectual junto ao Partido e ao Governo, apoiando-nos em seu traçado familiar e acadêmico, podemos considerá-lo como um intelectual experto, que desempenha funções tecnocráticas para a formulação e implantação de políticas públicas junto ao Governo do PT, que reivindica especialização para a solução de problemas concretos.

\section{CONSIDERAÇÕES FINAIS}

Para a nossa investigação, mesmo entendendo que toda classificação é arbitrária, não fugimos da tipificação dos intelectuais, porém temos por certo que não há como inseri-los em tipos puros ou fechados. Não nos afastamos, também, de categorias teóricas, para construir um núcleo de apoio à pesquisa e à análise da relação entre as posições principistas dos intelectuais do PT e a conformação da política pública da educação, buscando em posições plurais - Gramsci, Bourdieu e Weber - as perspectivas que possibilitassem a complementaridade teórica e amplitude necessária para a compreensão do problema de pesquisa.

Compreender as tensões vivenciadas pelos intelectuais levounos a atentar não somente para as semelhanças, diferenças e contradições entre a realidade da política pública e a produção discursiva desses intelectuais, mas, igualmente, para a lógica do Partido, suas próprias tensões e opções. É importante ponderar que, para aclarar as tensões desses personagens, não há como se pautar em explicações e resoluções rápidas, pois, além das variáveis já apontadas, há de se considerar que, como todos os seres humanos, são sujeitos a dúvidas e conflitos pessoais, teóricos ou práticos. E, ainda, reivindicar pensamento independente quando se executa pautas de Governo é um desafio para o intelectual que pode resultar em fratura à sua própria identidade.

Cabe reiterar que nossa investigação não reclama certezas, posicionamentos definitivos ou respostas universais, uma vez que, como vimos, os dilemas são múltiplos, as tensões distintas e a continuidade e descontinuidade dos discursos são particulares a cada 
Intelectuais do partido dos trabalhadores: princípios e tensões na política educacional

intelectual. Em face da complexidade do problema, e tendo claro que este trabalho é pleno de flancos abertos, deparamo-nos com outras possibilidades de exploração, aliadas ou não ao nosso marco de aproximação, a política pública da educação: quais tensões são vivenciadas pelo Presidente Luiz Inácio Lula da Silva frente ao caminho seguido pelo PT e pelo Governo? Como circulam as diferentes visões de mundo no interior do Partido e as suas interpretações para o consenso das decisões do PT e do Governo? Como se estabelece o sistema de posições e oposições dos intelectuais no interior do PT em face de suas diferentes tendências? Como se pode ver, muitas são as questões interrogantes que apontam a necessidade e possibilidade de futuras investigações!

\section{REFERÊNCIAS}

BOURDIEU, P. A economia das trocas simbólicas. São Paulo: Perspectiva, 1992.

BOURDIEU, P. Razões práticas: sobre a teoria da ação. Campinas, SP: Papirus, 1996.

BUARQUE, C. A cortina de ouro - os sustos do final do século e um sonho para o próximo. 2. ed. São Paulo: Paz e Terra. 1995.

BUARQUE, C. A desordem do progresso: o fim da era dos economistas e a construção do futuro. 4. ed. Rio de Janeiro: Paz e Terra. 1993.

BUARQUE, C. $\mathrm{O}$ colapso da modernidade brasileira: e uma proposta alternativa. 5. ed. Rio de Janeiro: Paz e Terra. 1991.

BUARQUE, C. A revolução nas prioridades: da modernidade técnica à modernidade ética. 2 ed. São Paulo: Paz e Terra. 1994.

de PAULA, J. H. M. Cristovam fez: a trajetória da UnB ao senado. Brasília, 2006.

GALLARDO. A. A. Intelectuales y expertos. Chile. Disponível em $<$ http:// www.palimpses tousach.cl/ALMENDRAS.doc >. Acesso em: 08 out. 2008.

GENOINO, J. PT, uma façanha política. In: PEREIRA, H. Entrevista. Revista Teoria e Debate. Área: $\mathrm{n}^{\circ}$ 62. abr. mai. 2005. Disponível em <www2.fpa.org.br/portal/ modules/news/article.php?storyid=3242>. Acesso em: 16 mar. 2008.

GENRO, T. Esquerda em processo. Petrópolis - RJ: Vozes, 2004.

GENRO, T. O futuro por armar: democracia e socialismo na era globalitária. Petrópolis - RJ: Vozes. 1999. 
GENRO, T. Utopia possível. 3. ed. Porto Alegre: Artes e Ofícios. 2004.

GENRO, T. Crise da democracia: direito, democracia direta e neoliberalismo na ordem global. Petrópolis - RJ: Vozes, 2002.

HADDAD, F. O sistema soviético: relato de uma polêmica. São Paulo: Scritta. 1992.

HADDAD, F. Trabalho e linguagem para a renovação do socialismo. Rio de Janeiro: Azougue Editorial. 2004.

LULA DA SILVA, L. I. Discurso de posse do presidente Luiz Inácio Lula da Silva pronunciado no Congresso Nacional. 01 jan. 2003. Disponível em: <http://www2.fpa.org.br/portal/modules/news/article. php? storyid=2296>. Acesso em: $24 \mathrm{dez} .2008$.

LULA DA SILVA, L. I. Carta ao povo brasileiro. Portal da Fundação Perseu Abramo. Disponível em: <http://www2.fpa.org.br/portal>. Acesso em: 24 dez. 2008a.

PT - PARTIDO DOS TRABALHADORES. Carta de princípios. Aprovada pela Comissão Nacional Provisória em 01 mai. 1979. Disponível em <http:// www.pt.org.br/portalpt/images/stories/arquivos/cartadeprincipios.pdf $>$. Acesso em: 16 mar. 2008.

PT - PARTIDO DOS TRABALHADORES. O socialismo petista. Disponível em: <www.pt.org.br/portalpt/images/stories/arquivos/osocialismopetista. pdf $>$. Acesso em: 16 mar. 2008.

PT - PARTIDO DOS TRABALHADORES. Manifesto de fundação. 21 out. 1980. Disponível em: <http://www.pt.org.br/portalpt/images/stories/ arquivos/manifesto.pdf>. Acesso em: 16 mar. 2008.

PT- PARTIDO DOS TRABALHADORES. Lula presidente - uma revolução democrática no Brasil: bases do programa de governo. 1994. Disponível em: <www.pt.org.br/pt25ano/sanos90/documentos94_revolucaodemocratica_brasil.pdf $>$. Acesso em: 07 jan. 2009.

WEBER, M. Textos selecionados. Trad. Maurício Tragdenberg et. al. 2.ed. São Paulo: Abril Cultural, 1980.

WEBER, M. Metodologias das ciências sociais. 3.ed. São Paulo: Cortez; Campinas-SP: Ed. UNICAMP, 2001.

WEBER, M. Ciência política: duas vocações. São Paulo: Martin Claret, 2002 .

Enviado em: 09/09

Aceito em: 12/09

Olhar de professor, Ponta Grossa, 12(2): 309-329, 2009. 